\title{
Scientific evaluation of modern clinical research: we need a new currency!
}

\author{
Markus W. Büchler • Markus K. Diener • Jürgen Weitz
}

Published online: 3 September 2011

(C) Springer-Verlag 2011

In the age of evidence-based medicine, clinical trials are playing an increasingly central role [1, 2]. While the approval of new medicinal products justifiably requires phase III randomized controlled trials, diagnostic procedures and nonpharmacological therapies should likewise be subjected to needs assessments and risk assessments using the criteria of evidence-based medicine [3]. Consequently, the future of clinical research - and with it also the future of medical decision making - will be based to a large extent on prospective clinical studies [4].

In keeping with the rising standards, most good medical journals now carry a section on "clinical trials" or even "randomized clinical trials" because such studies engender prestige and citations in the publishing world $[5,6]$. The Federal Coordinating Council for Comparative Effectiveness Research, the UK National Institute for Health Research, and the German medical research funding organizations, such as the Deutsche Forschungsgemeinschaft (German Research Foundation) and the Bundesministerium für Bildung und Forschung (Ministry for Education and Research), all now support clinical trials as well as systematic reviews and metaanalyses [7-9]. Despite all these efforts and despite clearly positive developments in the direction of more evidencebased medicine, now as before, there remains a huge gap between intention and reality: there are far too few appropriately powered clinical trials that can justifiably

M. W. Büchler $(\varangle) \cdot$ M. K. Diener $\cdot$ J. Weitz

Department of General, Visceral and Transplantation Surgery,

University of Heidelberg,

Heidelberg, Germany

e-mail: markus.buechler@med.uni-heidelberg.de be used to influence, even partially, the practice of medicine and surgery.

\section{Why is this so?}

Good clinical trials - especially when they are multicenterare cumbersome. They require complex, long-term planning, are difficult to execute due to differences in basic practices, and have become increasingly expensivenot the least because of all the necessary safeguards mandated by institutional review boards and ethics committees and of course the European Union Statutory Instruments, beginning with European Directive 2001/ 20/EC. Due to the multiple challenges and frustrations involved-ranging from bureaucracy to the difficulty of obtaining ethical permits-conducting this type of research is frequently a thankless job [10].

Young medical researchers today must carefully consider how to reach their goal of becoming a successful clinical academic. As a rule, well-planned laboratory research promises speedy enough success, and with it, the steps to an academic career can be more precisely planned. A translational or laboratory research project usually lasts for a specified period of 2-3 years, can be financed through realistic grant awards, and usually concludes with at least one publication. Some projects, which may at least partially overlap (over 3 to 6 years), can be completed while still working clinically and would be sufficient for a German "habilitation" ( $\mathrm{PhD})$. This in turn provides entrance to an academic career pathway, leading ultimately to a position as a university clinical professor.

In contrast, for a young researcher considering clinical trials as a pathway to academic advancement, 
the task seems almost impossible [11]. A good multicenter, randomized clinical trial normally requires 2 or more years of planning, 2 to 6 years of implementation, and then 1 to 2 years of analysis before publication [1214]. If a similar career goal can be reached in a much shorter time, a young medical researcher is very unlikely to choose the clinical trial career pathway, with the necessity of enduring some 6-10 years of concentrated effort for a single publication.

Are these two endeavors judged in a comparable way? Let's take for example surgical oncology. The results of a good research project in translational oncology or molecular biology conducted by a recognized laboratory research group might be published in a journal like Cancer Research (impact factor $>8$ ), and a randomized controlled trial in the area of oncological surgery, method A versus method B, might be published in the Annals of Surgery (impact factor $>7$ ), the highest ranked surgical journal. In the curriculum vitae of an applicant for a professorship, these two publications might appear to have equal weight. But they are not of equal value, either in terms of the time and effort involved in achieving the output (publication), or in what ultimately matters-the impact on clinical practice.

\section{How can we adjust for this discrepancy?}

For clinical studies, a multiplication factor needs to be considered, which can be used together with a base value (for example, the impact factor of a journal [15]) to assign a score to the particular study. Considering only the parameter of time, there is already a factor of 3 to 10 times in favor of clinical trials, depending on the point of view. Furthermore, the costs of a good clinical trial-currently averaging some $1,000,000 €$ or more-give a factor of around 5 times compared to the cost of a good piece of laboratory-based research [16, 17]. In addition, the demands on social competency needed by a researcher conducting a multicenter randomized controlled trialincluding motivating the teams involved and standardization of different local practices - support a multiplication factor of 5 in comparison to laboratory-based work, where the levels of coordination and standardization required are much less.

Times 3, times 5 , or even times 10 , how big should the multiplication factor be that is assigned to the activity required for the successful conclusion of a clinical trial? In order for the future of medicine to be built on a stronger foundation of clinical study evidence, a new currency is needed for the evaluation of clinical research activity. In order to support the reorientation of young medical researchers toward clinical trials, a multiplication factor of
$5-10$, depending on the quality and complexity of the study, would seem to be justifiable.

Patient advocacy organizations and politicians continue to call for more clinical evidence in medicine. Unless we change our system of evaluating research efforts, progress in clinical research will be considerably slower than it could and should be.

Conflicts of interest None.

\section{References}

1. Diener MK, Simon T, Büchler MW, Seiler CM (2011) Surgical evaluation and knowledge transfer-methods of clinical research in surgery. Langenbecks Arch Surg. doi:10.1007/s00423-011-0775-x

2. Russell TR (2010) Report from the American College of Surgeons: a 10-year review and a look to the future. Arch Surg 145:399-400

3. Barkun JS, Aronson JK, Feldman LS, Maddern GJ, Strasberg SM, Collaboration B (2009) Evaluation and stages of surgical innovations. Lancet 374:1089-1096

4. Diener MK, Wolff RF, von Elm E, Rahbari NN, Mavergames C, Knaebel HP, Seiler CM, Antes G (2009) Can decision making in general surgery be based on evidence? An empirical study of Cochrane Reviews. Surgery 146:444-461

5. Schneider M, Weitz J, Büchler MW (2010) The focus of Langenbeck's Archives of Surgery in the 21st century. Langenbecks Arch Surg 395(Suppl 1):63-67

6. Urbach DR, Morris AM (2010) Health care reform and comparative effectiveness: implications for surgeons. Arch Surg 145:120 122

7. Federal Coordinating Council for Comparative Effectiveness Research: http://www.hhs.gov/recovery/programs/cer/index.html

8. Individual Grants Programme, Deutsche Forschungsgemeinschaft: http://www.dfg.de/en/research_funding/individual_grants_ programme/clinical trials/index.html

9. Blazeby JM (2009) Opportunities for randomised surgical trials. Bull Roy Coll Surg Engl 91:202-203

10. Ergina PL, Cook JA, Blazeby JM, Boutron I, Clavien PA, Reeves BC, Seiler CM, Collaboration B (2009) Challenges in evaluating surgical innovation. Lancet 374:1097-1104

11. Bohrer T, Koller M, Schlitt HJ, Bauer H, German Society of Surgery (2011) Workload and quality of life of surgeons. Results and implications of a large-scale survey by the German Society of Surgery. Langenbecks Arch Surg 396:669-676

12. Seiler CM, Bruckner T, Diener MK, Papyan A, Golcher H, Seidlmayer C, Franck A, Kieser M, Büchler MW, Knaebel HP (2009) Interrupted or continuous slowly absorbable sutures for closure of primary elective midline abdominal incisions: a multicenter randomized trial (INSECT: ISRCTN24023541). Ann Surg 249:576-582

13. Neoptolemos JP, Stocken DD, Friess H, Bassi C, Dunn JA, Hickey H, Beger H, Fernandez-Cruz L, Dervenis C, Lacaine F, Falconi M, Pederzoli P, Pap A, Spooner D, Kerr DJ, Büchler MW, European Study Group for Pancreatic Cancer (2004) A randomized trial of chemoradiotherapy and chemotherapy after resection of pancreatic cancer. N Engl J Med 350:1200-1210

14. Fischer L, Deckert A, Diener MK, Zimmermann JB, Büchler MW, Seiler CM (2011) Ranking of patient and surgeons' perspectives for endpoints in randomized controlled trials-lessons learned from 
the POVATI trial [ISRCTN 60734227]. Langenbecks Arch Surg. doi:10.1007/s00423-011-0798-3

15. Rieder S, Bruse CS, Michalski CW, Kleeff J, Friess H (2010) The impact factor ranking - a challenge for scientists and publishers. Langenbecks Arch Surg 395(Suppl 1):57-61

16. Seiler CM, Kellmeyer P, Kienle P, Büchler MW, Knaebel HP, INSECT Study Group (2007) Assessment of the ethical review process for non-pharmacological multicentre studies in Germany on the basis of a randomised surgical trial. J Med Ethics 33:113-118
17. Diener MK, Seiler CM, Rossion I, Kleeff J, Glanemann M, Butturini G, Tomazic A, Bruns CJ, Busch OR, Farkas S, Belyaev O, Neoptolemos JP, Halloran C, Keck T, Niedergethmann M, Gellert K, Witzigmann H, Kollmar O, Langer P, Steger U, Neudecker J, Berrevoet F, Ganzera S, Heiss MM, Luntz SP, Bruckner T, Kieser M, Büchler MW (2011) Efficacy of stapler versus hand-sewn closure after distal pancreatectomy (DISPACT): a randomised, controlled multicentre trial. Lancet $377: 1514-1522$ 